\title{
Feature of the vortex and the jet flows around and inside the three-row pile group
}

\author{
A.V. Voskobijnyk \& V.A. Voskoboinick \\ Department of Hydrobionics and Boundary Layer Control, \\ Institute of Hydromechanics of the NAS of Ukraine, Kyiv, Ukraine \\ O.A. Voskoboinyk \\ Department of Technical Hydromechanics, \\ Institute of Hydromechanics of the NAS of Ukraine, Kyiv, Ukraine \\ L.M. Tereshchenko \& I.A. Khizha \\ Department of Engineering Hydrodynamics, \\ Institute of Hydromechanics of the NAS of Ukraine, Kyiv, Ukraine
}

\begin{abstract}
In this article the results of experimental research of kinematics and the dynamics of horseshoe vortex structures, wake vortices and lateral jet flows, formed around and inside the pile group of three-row grillage, set on a flat rigid surface and sand soil, are presented. Visualization of flow is conducted using water soluble coatings and contrast substances, introduced into the stream. The fields of velocity, pressure and shear stresses around and inside the pile construction were investigated using the miniature sensors of the velocity, dynamic pressure and pressure fluctuations. The place of formation and features of development of large-scale horseshoe vortex structures and wake vortices, and the hydrodynamic characteristics of the vortex and jet flow were determined. The space-time correlation and spectral characteristics of the velocity and pressure fluctuations were measured. The scale of the coherent vortex structures, their frequencies of rotations and oscillations, convective velocities and direction of transfer were determined. The three-dimensional spectrograms and correlograms of vortex and the jet flow about and inside the three-row pile grillage were obtained.
\end{abstract}

\section{INTRODUCTION}

Very often a complex or group of piers embedded in bridge construction cause a global scour of soil around the bridge construction along with a local scour of individual piers.

The global scour is produced by the horseshoe vortex structures that envelop the entire complex of piers. The mechanism of generation and formation of horseshoe vortices is the same as for the single pier, but the flow of complex piers is an combination of vortex flows generated by each element of bridge construction. Vortex interaction depends from the number of hydrodynamic and hydrological parameters and significantly changes from the shape and design of pier group. This fact imposes certain restrictions on the numerical and experimental evaluation of features and generation of vortex structures near the piers and their influence on surrounding soil.

Around the bridge piers there is a fairly wide range of the turbulent scales that govern the process of ground transport. Regardless of shape of pier, one of the main mechanisms that govern the formation and subsequent evolution of the scour hole is the generation of necklace-like vortex structure, usually known as horseshoe system (Akilli \& Rockwell 2002, Ataie-Ashtiani \& Aslani-Kordkandi 2012, Dargahi 1990, Melville 1997). To understand the mechanism of soil erosion it is needed to describe the coherent vortices horseshoe system in various flow regimes and to define this effect in a flow under the bottom of the river and near the base of pier.Adverse pressure gradient caused by pier initiates separation of incoming boundary layer and the formation of a line of separation on the bottom surface around the pier

These longitudinal adverse pressure gradients also lead to the formation of necklace-like vortices around the front part of the pier base (Kirkil \& Constantinescu 2015, Melville1997, Roulund et al. 2005). Primary horseshoe vortex structure has same direction of rotation as the vorticity in an oncoming boundary layer. Horseshoe vortex is drawing around a pier and is curving around its front part near a bottom partially because of transverse pressure gradients. Consequently, the lateral vortex lines are oriented in longitudinal direction and vorticity are oppositely directed on both sides of streamlined pier. A high velocity liquid along the front part of pier moves towards bottom and is usually called a down flow. As a result of interaction between the down flow, bottom and horseshoe vortex systems the drag around the front part of support increases. In the case of a turbulent flow of the location, the scale and the intensity of the horseshoe vortices varies greatly over time. They generate high turbulence, velocity and pressure fluctuations and form significant shear stresses on bottom, leading to erosion of soil near the streamlined piers (Ettema et al. 2006, Voskoboinick et al. 2014). To understand how the flow erodes the 
soil around the piers it is needed to study and to describe the structure of these large-scale coherent vortex structures and small-scale vortices and their interaction with the streamlined surface and ground in various stages of process of erosion.

The purpose of this work is to determine the mechanism of formation and development of vortex structures generated by the junction flow around and inside the bridge pier model in the form of three-row pile grillage, and also to study the features of vortex and jet flows responsible for the formation of local and global scours near the group construction of the pier.

\section{EXPERIMENTAL SETUP}

Experimental studies were carried out in a hydrodynamic channel and flume of hydraulic laboratory of Institute of hydromechanics of the National Academy of Sciences of Ukraine. The channel with the rigid bottom and the open water surface had a length of $14 \mathrm{~m}$, a width of $0.8 \mathrm{~m}$ and a depth of $0.8 \mathrm{~m}$. The flume with the sandy bed had a length of $14 \mathrm{~m}$, a width of $1.5 \mathrm{~m}$ and a depth of $0.9 \mathrm{~m}$. Mean dimensions of particles of the quartz sand were $d_{50}=0.35 \mathrm{~mm}$. The measuring sections were located at a distance of $6 \mathrm{~m}$ from the input channel and $8 \mathrm{~m}$ from the input flume. The channel walls were made from transparent thick glass, which made it possible to carry out visual research. The water in the hydrodynamic channel and flume was fed by a pump through a soothing chamber, confuser, honeycombs and grids.

Hydraulically smooth plate with a length of $2 \mathrm{~m}$, a thick of $0.01 \mathrm{~m}$ and a width of $0.5 \mathrm{~m}$ was settled above the bottom of measuring section of channel at on a height of $0.1 \mathrm{~m}$. The model of the three-row pile grillage was mounted along the longitudinal axis of plate at a distance of $1 \mathrm{~m}$ from its frontal edge. $>$ Grillage consisted from 31 cylindrical piles with a diameter of $d=0.027 \mathrm{~m}$, located in three rows in a staggered manner (Voskoboinick 2008). The length of the grillage is $0.6 \mathrm{~m}$, the width $(b)$ is $0.1 \mathrm{~m}$ and the height is $0.2 \mathrm{~m}$. The flow depth $(H)$ in the experiments was constant $-0.2 \mathrm{~m}$. The flow velocity $(U)$ decreased from $0.06 \mathrm{~m} / \mathrm{s}$ to $0.4 \mathrm{~m} / \mathrm{s}$. Reynolds numbers and Froude numbers are $R e_{x}=U x / v=(60,000$ 400,000), $\quad R e_{d}=U d / v=(1620-10,800), \quad R e_{b}=U b / v=$ $(6000-40,000)$ and $F r=U /(g H)^{0.5}=(0.04-0.29)$, correspondingly, where $x$ is the longitudinal distance from the frontal edge of flat plate to the first central pile grillage in the flow direction; $v$ - kinematic viscosity of water, $g$ - acceleration of free fall.

In the hydrodynamic flume the flow depth was increased from $0.17 \mathrm{~m}$ to $0.4 \mathrm{~m}$ and the flow velocity was increased from $0.15 \mathrm{~m} / \mathrm{s}$ to $0.6 \mathrm{~m} / \mathrm{s}$. For these regimes of the flow and the depths the Reynolds numbers and the Froude numbers were taken as $R e_{b}=(6000-67,000)$ and $F r=(0.08-0.45)$.

Visualization was performed using water-soluble ink and dyes (Voskoboinick et al. 2008) that were administered in the research area of flow through tiny tubes, and applying contrasting coating which is washed off the water flow with the streamlined surface. Monitoring of movement of dyes and erosion coatings, as well as processing and analysis of video and photographic materials, made it possible to register a zones of the greatest erosion of contrast medium near piles, scale, convective velocity and the rotation velocity of vortex structures in these areas. Measuring of the velocity field performed in areas with generated the coherent vortex structures in form of horseshoe vortices, wake vortices and the lateral jets. The kinematic characteristics of junction flow were measured by designed and developed miniature thermistor sensors of the velocity and piezoresistive sensors of dynamic pressure (Voskoboinick 2008). To obtain the cross statistical characteristics the thermistor velocity sensors (with diameter of sensitive surface $0.8 \mathrm{~mm}$ ) were mounted using special holders in the correlation block (with a fixed distance between the two sensors).

Control of flow velocity was carried out using the gauge-type sensor type of Pitot tube of double pressure. Electrical signals from the sensors were sent to the special two-channel spectrum analyzer Brüel \& Kjaer and then through the appropriate analog-todigital converters were transferred to personal computers, where experimental data were processed and analyzed using standard and special designed programs based on the theory of probability and mathematical statistics.

All measurements, monitoring and recording equipment were tested and calibrated in accordance with the procedure of passport data and the procedure of experiments. The sensors are certified and checked trough absolute and relative methods at specialized stands and related equipment. Measurement error of the integral and mean velocities did not exceed $4 \%$ (with the reliability 0.95 or $2 \sigma$ ), the velocity fluctuations - up to $6 \%$, spectral characteristics up to $2 \mathrm{~dB}$ in the frequency range from $0.2 \mathrm{~Hz}$ to $1000 \mathrm{~Hz}$.

\section{MEASUREMENT RESULTS}

The distribution of shear stresses demonstrates visual research with the application of water-soluble contrast materials on the streamlined flat surface where was placed the three-row grillage model. Figure 1 shows a picture of the contrast coating location on the plate surface with three-row grillage, for the velocity flow $0.1 \mathrm{~m} / \mathrm{s}$, Reynolds number $R e_{d}=2700$ and Froude number $F r=0.07$. Water washes away a contrast coating before each streamlined piles. Here are 
generated intense vortex structures (horseshoe and wake vortices), as well as lateral flow due to the features of the group pile construction. Large part of the contrast coating is washed away between the first and the second and also the next to last and the last lateral piles where there are the lateral flows. Also intensive scour of coating is observed before the front of group of piles. Here is formed an intense horseshoe vortex system as a result of interaction of incoming flow with the bluff body construction of the three-row pile grillage (Fig. 2). The presence of intense shear stress at the marked locations of streamlined surface leads to considerable erosion of soil. This observation was confirmed by numerical and experimental research (Ettema et al. 2006, Kirkil \& Constantinescu 2015, Sumer et al. 2005, Voskoboinick et al. 2007).

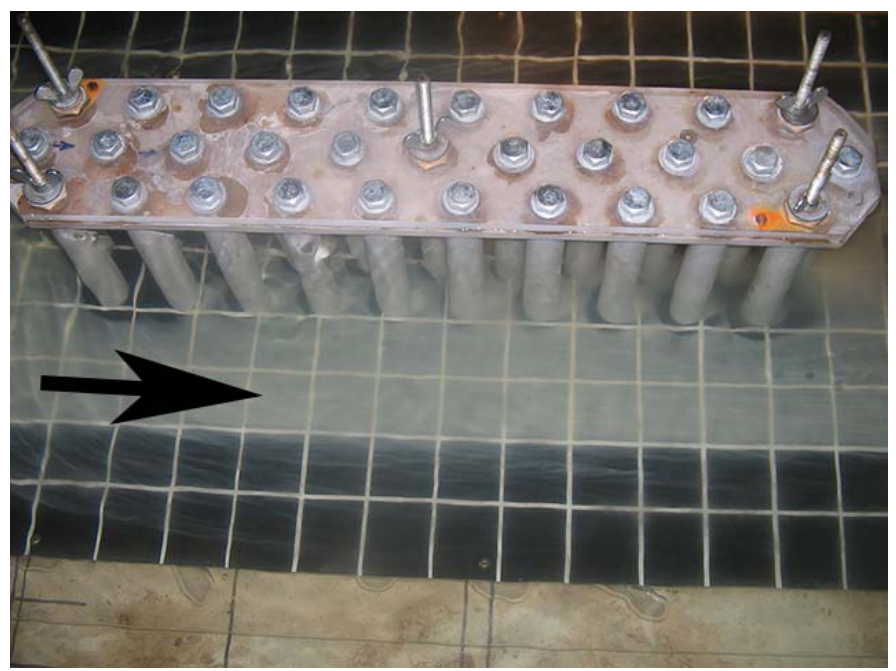

Figure 1. Scour of water-soluble contrast coatings on the streamlined flat surface around and inside the three-row pile grillage

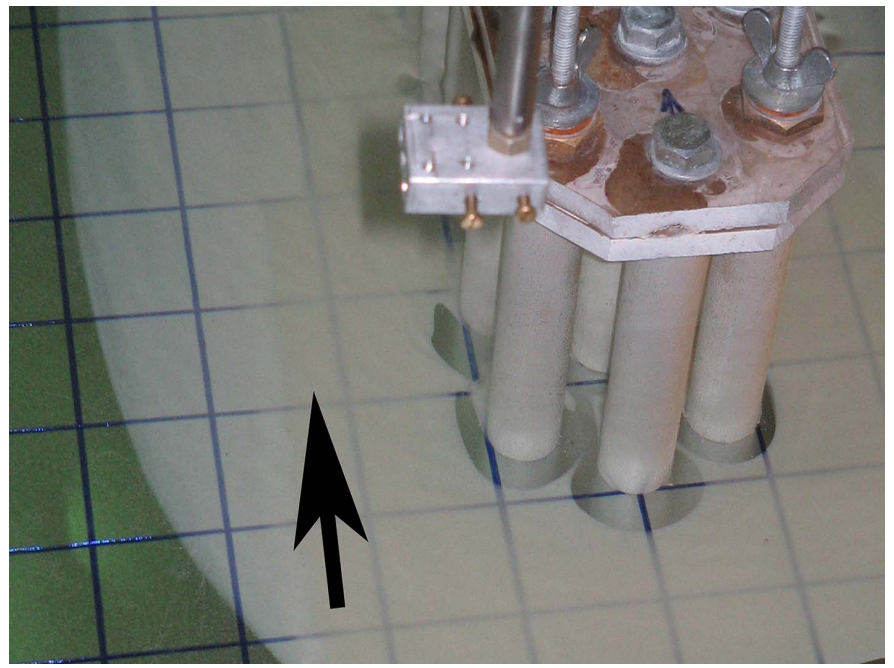

Figure 2. Scour of water-soluble contrast coatings on the streamlined flat surface before and inside the three-row pile grillage
The erosion of soil has both local and global character, due to the features of the junction flow near the three-row pile grillage. The local scour is shaping in front of each pile of grillage and global scour is shaping in front of all construction of the three-row pile grillage (Fig. 3). The highest scour hole is observed in front of the front group of grillage piles. In the middle of the grillage observed the alluvium of sand soil and downstream (aft group of the piles). Also it is observed the erosion of soil (Fig. 4).As it is shown in article (Voskoboinick et al. 2008), the symmetrical street eddies from the vertical wake vortices are initiating after the front central pile of the three-row grillage.

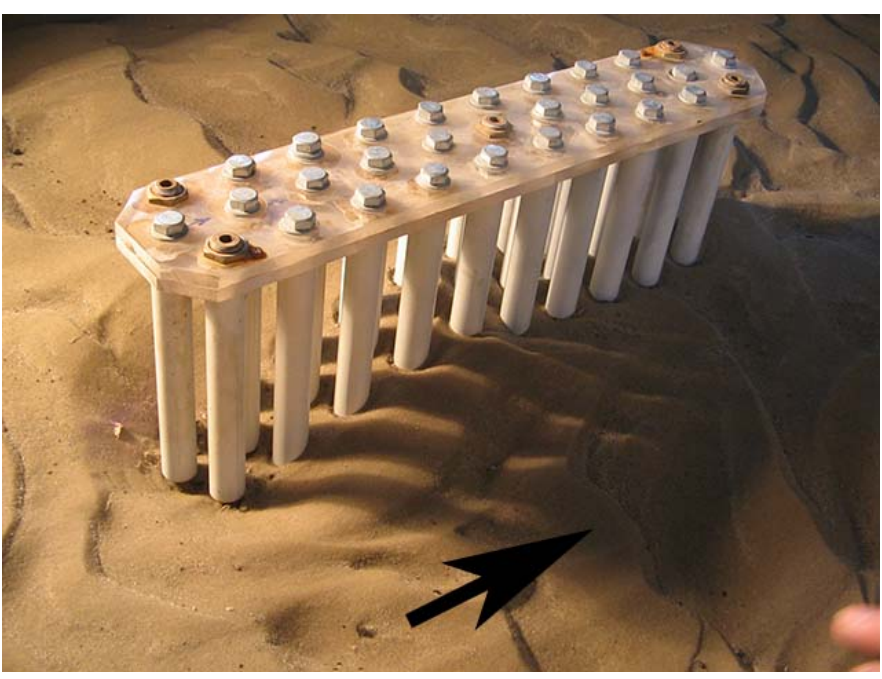

Figure 3. Local and global scour before the three-row pile grillage

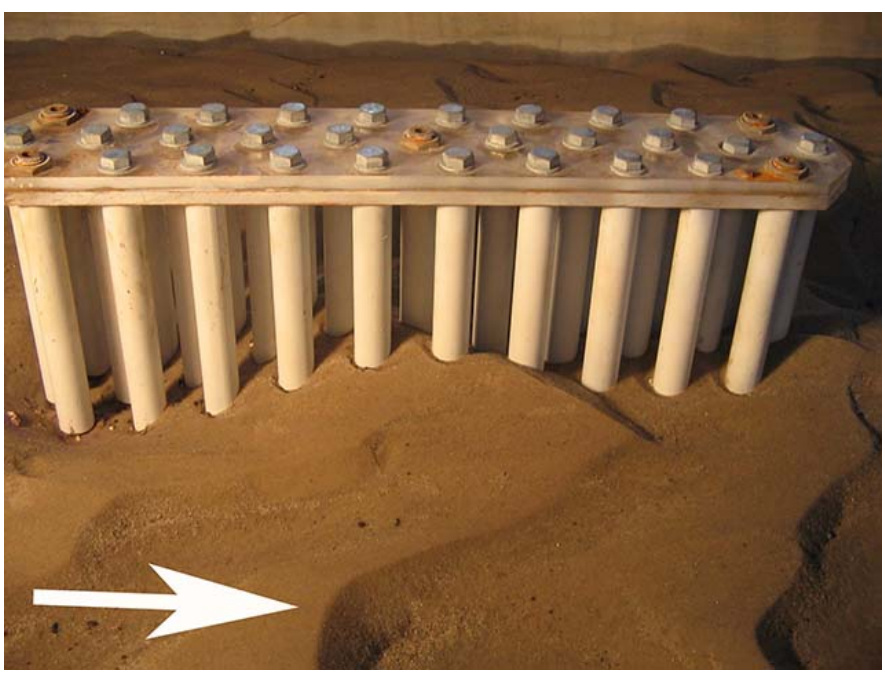

Figure 4. Erosion of sand soil around and inside the three-row pile grillage

The symmetry of counter-rotating vertical vortices is greatly disturbed behind the lateral piles, especially in the presence of the intense lateral flow (the first and the next to last pile). One of circuits of wake vortices was initiated at a distance of almost $(0.2-0.4) d$ along the outer lateral edge of three-row construction under flow velocity of $0.1 \mathrm{~m} / \mathrm{s}$. Other 
circuit of wake vortices (rotating in opposite direction relative to the first) is generated at a distance of approximately (0.4-0.6) $d$ behind the first lateral cylinder. Formation of these asymmetric wake vortices occurs periodically with the one aft side of the first lateral cylinder to the other one. The frequency of occurrence of wake vortices between the first two lateral cylinders is about $f=0.5 \mathrm{~Hz}$ (the Strouhal number is $S t=f d / U=0.14$ ).

When intensity of lateral flow is decreased (this coincides with a phase of wake vortex formation behind the first central pile and horseshoe vortex system around it), in the wake of the first lateral pile is generated the pair of counter-rotating symmetric wake vortices (Voskoboinick et al. 2008). The internal wake vortex moves downstream with greater convective velocity under the influence of lateral flow and closers to the external wake vortex in motion (Fig. 5). In general, all wakes vortices generated behind the lateral piles and lateral flows are combined with large-scale horseshoe vortex to form an unstable vortex flow from each side of the three-row pile grillage.

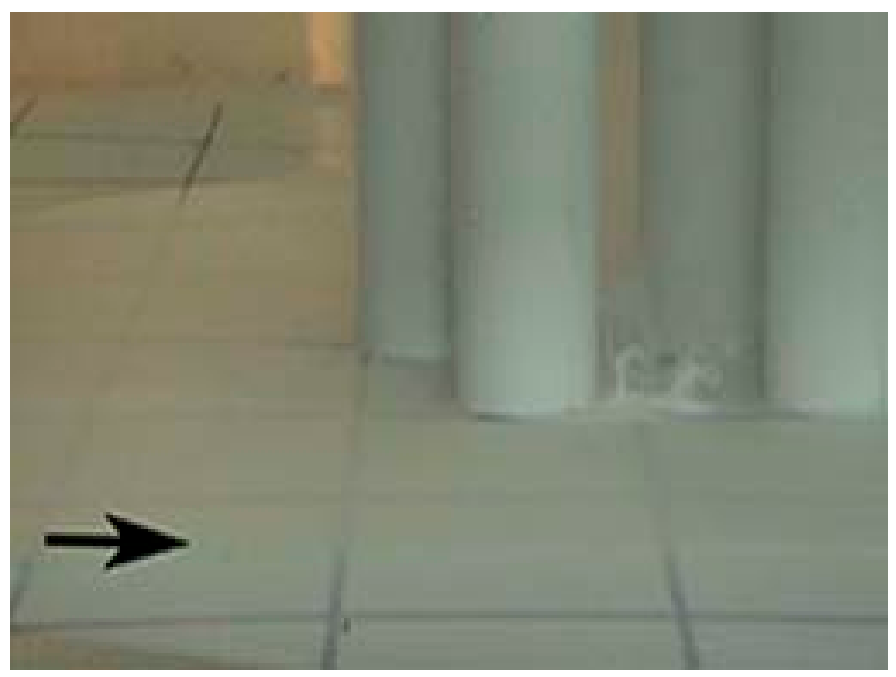

Figure 5. Generation of pair of the counter-rotating symmetric wake vortices between first and second lateral piles.

Experimental research of the velocity field with the miniature thermistor sensors shows that inside of gap between the lateral piles there are high longitudinal and transversal mean velocities and velocity fluctuations (especially between first and second ones, and between last and next to the last lateral pile). Such a high values of velocity lead to interaction between the lateral flow and piles, horseshoe vortices, formed in the front of each of piles, and wake vortices, generated by the piles located upstream. Changes to the time of mean velocity and velocity fluctuations in front of the second lateral pile compared to the same velocity components to the first central pile, and the spectrum of field of velocity fluctuations in the periphery and in the core of horseshoe vortices are shown at figures 6-8.
At these figures the curves 1 and 3 represent the value of velocity in the core of horseshoe vortices, and curves 2 and 4 show the value of velocity in the periphery of vortices, formed in front of the central and second lateral piles, respectively. In accordance to the results presented in article (Voskoboinick 2008), quasistable vortex approximately $9 \mathrm{~mm}$ in diameter is formed before the central pile for a given flow regime. The core of the vortex is located at a distance of (0.15-0.2) $d$ before the front surface of the pile and about $(0.1-0.15) d$ from the streamlined surface of flat plate. According to the results of research (Voskoboinick 2008), quasistable vortex with the scale $0.5 d$ and $0.4 d$, respectively in the horizontal $(x$ axis) and vertical ( $y$ axis) directions is formed before the front surface of the second lateral pile. The core of this quasistable horseshoe vortex located in the region with coordinates $x=(0.25-0.3) d ; \quad y=(0.15$ $0.2) d$. The horseshoe vortex had an egg-shaped form elongated in the horizontal direction. Sharp part of the horseshoe vortex is found closer to the aft of the first lateral pile. The value of the mean velocity in the core and on the periphery of this large-scale vortex is at (25-35)\% higher than the appropriate value for quasistable vortex before the first central pile (see Fig. 6).

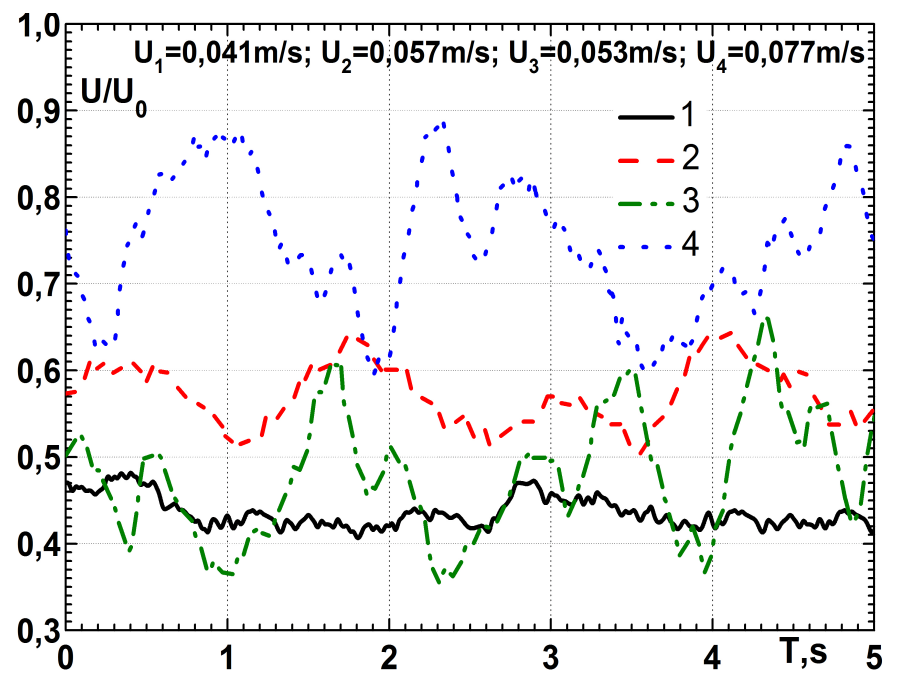

Figure 6. Changes in the time of mean velocity before central and second lateral piles of the three-row pile grillage.

In addition, there are significant oscillations in the core of vortex system at the front of the second lateral pile relative to the core of horseshoe vortex, forming before the front surface of central pile of the three-row grillage. Due to influence of oscillating lateral flow, and the wake vortices formed behind the first lateral pile, the core of horseshoe vortex, formed around the second lateral pile, strongly fluctuating. The frequency of these oscillations was relatively large and had a wide frequency spectrum.

Both inside the horseshoe vortex and near it the field of velocity fluctuations before the second lateral pile was also more intense at (20-25)\% comparing to the results of velocity fluctuations before the 
center pile (see Fig. 7). However, it should be noted that the turbulence intensity as a ratio of root-meansquare values of velocity fluctuations to the mean local velocity $\left(u^{\prime} / U\right)$, makes up $12 \%$ and $50 \%$, respectively, in the core and the periphery of quasistable horseshoe vortex before the first central pile, and before the second lateral pile it is $7 \%$ and $29 \%$. The reduction in turbulence intensity before the second lateral pile was the result of a significant increase in mean velocity of vortex flow with respect to velocity fluctuations (see Figs 6, 7).

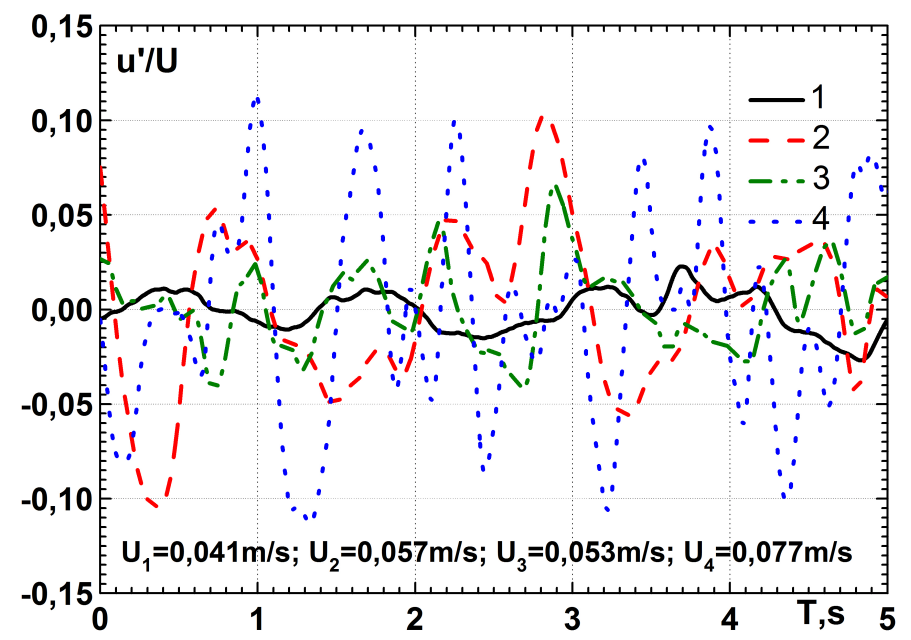

Figure 7. Changes in time of velocity fluctuations before central and second lateral piles of the three-row pile grillage.

Figure 8 shows the dependencies of normalized power spectral density of velocity fluctuations (where $P^{*}(f)=P^{2}(f) d /\left(u^{\prime}\right)^{2} \cdot U$, and $S t=f d / U$ ). Here the area under each curve or the total energy of the velocity fluctuation field is equal to one (Vinogradnyi et al. 1989, Voskoboinick 2012, Voskoboinick et al. 2013). The spectral characteristics of field of velocity fluctuations before the second lateral pile are filled with up to $25 \mathrm{~Hz}(S t=6)$, as shown in figure 8 , because of interaction of horseshoe vortex structures, the wake vortices and the lateral flows between the piles. Increase of the intensity of high-frequency components of the velocity fluctuations at this area indicates that there are small-scale sources of velocity fluctuations, which may be the small eddies formed by the decay of coherent large-scale vortices. Maxima of the power spectral density of the velocity fluctuations are focused on the frequencies (0.6$1.0) \mathrm{Hz}$ or $S t=(0.16-0.27)$ and $(0.9-1.5) \mathrm{Hz}$ or $S t=(0.24-0.41)$ for horseshoe vortices before the front central pile and before the second lateral pile of the three-row grillage. In periphery of vortex structures the frequencies of velocity fluctuations were higher than in the core one. These frequencies corresponding to the most intense oscillations of field of velocity fluctuations in the vortex flow caused by the rotation frequency of the horseshoe vortex system and its oscillations in the space around the piles (Voskoboinick et al. 2014).

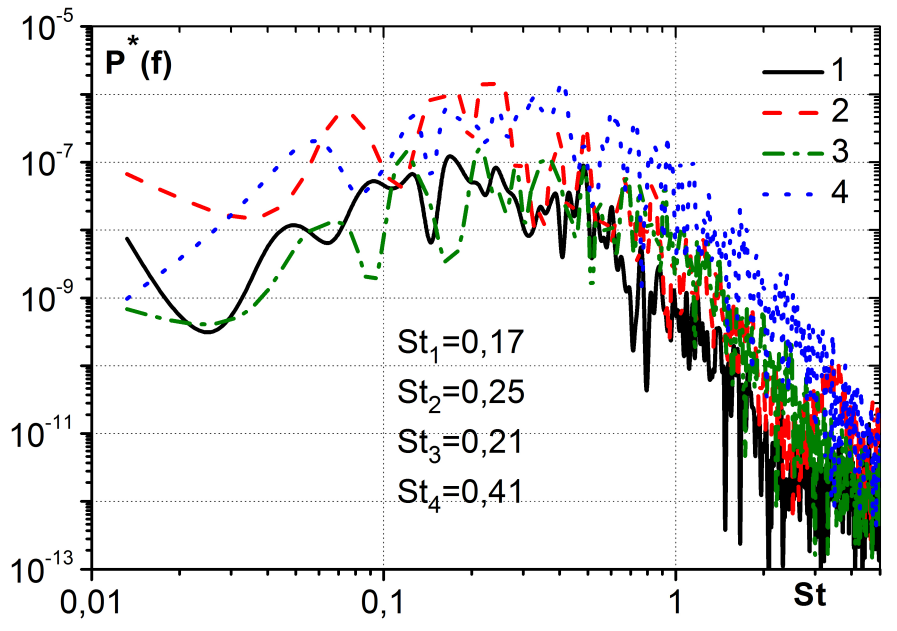

Figure 8. Power spectral density of velocity fluctuations before central and second lateral piles of the grillage.

The change in time of spectral characteristics shown in figure 9 in the form of three-dimensional spectrogram, where the observation time in seconds, the frequency in $\mathrm{Hz}$ and the spectral power density of velocity fluctuations in $(\mathrm{m} / \mathrm{s})^{2} / \mathrm{Hz}$ were shown on the corresponding axis. This spectrogram clearly describes the nonstationarity of a random process, characterizing the velocity fluctuation field before the front part of the central pile. Here are clearly observed periods of formation and development of the quasistable horseshoe vortex, the convective velocity and the degree of energy transformation between the frequency components in the formation process and oscillations in space and in time, both horseshoe vortices, so and surrounding vortex flow. Thus, the rotation frequency of the vortex is around $(1-1.5) \mathrm{Hz}$, the vortex oscillations in the vertical and horizontal plane is almost $(0.45-0.75) \mathrm{Hz}$.
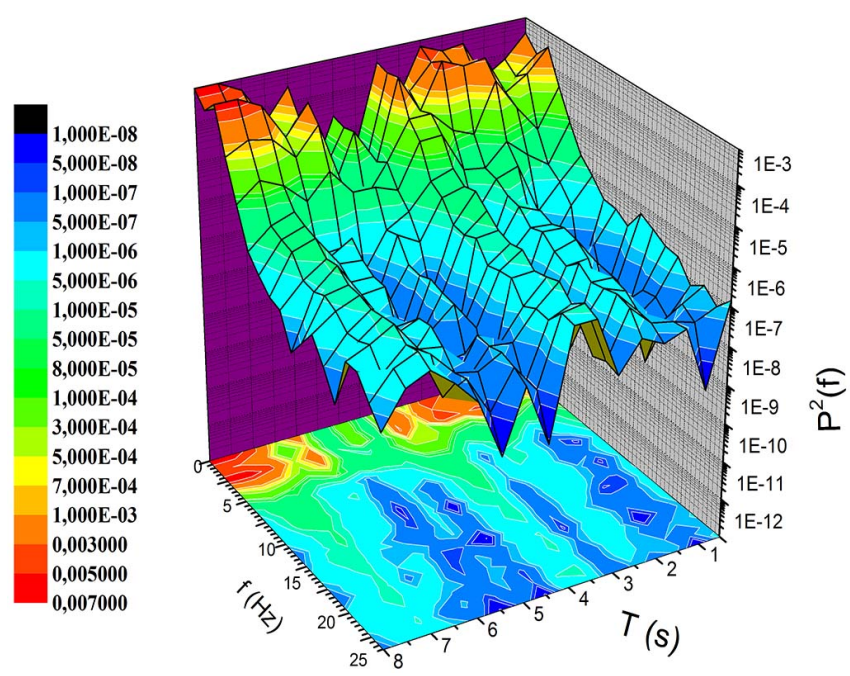

Figure 9. Spectrogram of velocity fluctuations before the front part of the central pile of the three-row pile grillage.

Measurement of space-time or cross correlation between signals of pair velocity sensors, located at a fixed distance from each other, showed that these statistical correlation characteristics are substantially 
nonstationary and inhomogeneous both in time and in space. Their values differ depending on the initial time of data registration and from the interval of statistical processing, as well as on the location and the distance between the sensors. It is caused by the instability of vortex motion in the studied volumes of the junction flow and the significant nonstationarity of interaction between the vortices and with the streamlined surface, and also by the presence of lateral oscillating flows between piles of the three-row grillage (Voskoboinick 2008, Voskoboinick et al. 2014). The methods of short-term or immediate registration of information and statistical analysis of experimental data were used. Space-time correlations between the pair of sensors of velocity fluctuations were analyzed using the fast Fourier transform algorithm for the time period of 0.5 seconds, does not exceeding the period of formation of the quasistable vortex structures formed near the streamlined piles and their rotation frequencies, obtained from spectral analysis data.

Figure 10 shows the space-time correlogram of the velocity fluctuations between the pair velocity sensors, which are set at a fixed distance $(4 \mathrm{~mm}$ from each other in the direction of " $x$ " and $1 \mathrm{~mm}$ in the direction of " $y ")$, in the three-dimensional form for the flow velocity of $0.1 \mathrm{~m} / \mathrm{s}, R e_{d}=2700$ and $F r=0.07$. This correlogram was obtained it the junction flow between the first and second lateral piles of the three-row grillage. For orthogonal coordinates were marked the cross-correlation coefficients $\left(\rho_{12}(\tau)\right)$, normalized by the root-mean-squares of velocity fluctuations in the measuring points, the delay time of correlation signal $(\tau)$ and the time interval of short-time statistical analysis of data $(T)$, measured in seconds. An interchange of the significant correlations between the experimental points with a frequency close to $1.5 \mathrm{~Hz}$, and also the emergence of anticorrelations (velocity fluctuations are in the antiphase) with a frequency of $0.5 \mathrm{~Hz}$ provides possibility to estimate the rotation frequency of quasistability coherent vortex structures, formed in the vortex flow, and their oscillations in space. The values of cross correlation coefficients indicate the degree of the correlation of velocity fluctuations inside a flow and their sources (e.g. the horseshoe and the wake vortex systems).

Delay time of the correlation signal and it sign with a fixed distance between the velocity fluctuation sensors allows to obtain the transfer velocity and the direction of motion of coherent vortex structures or sources of correlated velocity fluctuations (Vinogradnyi et al. 1989, Voskoboinick et al 2003, Voskoboinick 2008). For these conditions, the maximum of the cross-correlation coefficient of velocity fluctuations was registered for the delay time of approximately $0.07 \mathrm{~s}$ and the cross-correlation coefficient was 0.92 , which was observed between 4 and 5 seconds in figure 10.

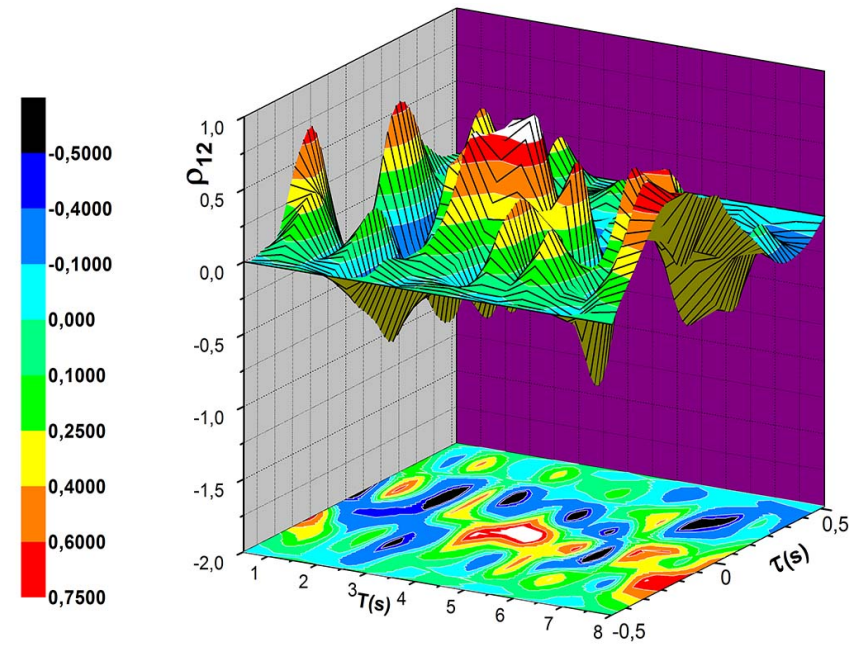

Figure 10. Correlogram of velocity fluctuations before the front part of central pile of the three-row pile grillage.

For the fixed distance between velocity sensors and certain time delay of a maximum of crosscorrelation coefficient, the convective velocity of correlated signal was approximately $U_{c}=0.7 U$. In our view, this is a circular velocity of the quesistability large-scale horseshoe vortex, formed before the second lateral pile, observed in visual investigations. In consideration of the rotation frequency close to $1.5 \mathrm{~Hz}$ (see Figs 9, 10), we can estimate the quivalent radius of the vortex, $R_{v}=U_{c} / \omega$, where $\omega$ - angular frequency $(\omega=2 \pi f)$, which is equal to (6-7) $\mathrm{mm}$ or almost $0.25 \mathrm{~d}$. This equivalent radius of the horseshoe vortex similar to the scales of the horseshoe vortex, formed before the second lateral pile, and identified with the mean velocity profiles (Voskoboinick 2008, Voskoboinick et al. 2014) in this region of junction flow, as mentioned above.

\section{CONCLUSIONS}

It was registered that before and between the piles of the three-row grillage is generated horseshoe vortex systems, wake vortices and lateral jet flows, intensity of which has the highest value between the first and second, and between next to last and last lateral piles, which leads to the appearance in these areas of junction flow the high shear stresses on the streamlined surface.

It was established that the highest scour hole is observed before the front group of grillage piles. The local scour is formed before each pile of the grillage and the global scour is formed before all construction of the three-row pile grillage. The alluvium of sandy soil occurred in the middle of the grillage and the erosion of soil again observed in the region of aft group of piles.

It was found that the value of the mean velocity in core and on periphery of the large-scale vortex before second lateral pile at $(25-35) \%$ higher than quasistable vortex before the first central pile. The tur- 
bulence intensity draws up $12 \%$ and $50 \%$, respectively, in the core and on the periphery of the quasistable horseshoe vortex before the first central pile, and before the second lateral pile it is $7 \%$ and $29 \%$, respectively.

It was shown that spectral characteristics of the velocity fluctuation field before the second lateral pile filled up to $25 \mathrm{~Hz}$ or $S t<7$, and before the first central pile - up to $10 \mathrm{~Hz}$ or $S t<3$ through interaction of horseshoe vortex structures, wake vortices and lateral jet flows between the piles. Maxima of the power spectral density of velocity fluctuations occured on the frequencies $(0.6-1.0) \mathrm{Hz}$ or $S t=(0.16$ $0.27)$ and $(0.9-1.5) \mathrm{Hz}$ or $S t=(0.24-0.41)$ for horseshoe vortices before the front central pile and before the second lateral pile of the three-row grillage, respectively. The frequency of velocity fluctuations on the periphery of the vortex structures is higher than in the core.

It was determined that the cross spectral and correlation characteristics of junction flow nearby the three-row pile grillage have significantly nonstationary and inhomogeneous character both in time and in space. Interchange of significant correlations between experimental points with a frequency close to $1.5 \mathrm{~Hz}$, and the emergence of anticorrelations with a frequency of $0.5 \mathrm{~Hz}$ provides possibility to estimate the rotation frequency and their oscillations in space of quasistability coherent vortex structures, formed in the vortex flow before the second lateral pile.

It was defined that large-scale coherent horseshoe vortex system formed near the second lateral pile of the three-row grillage, had a larger size and convective velocity than quasistability horseshoe vortex structure generated before the first central pile. This vortex had an equivalent diameter of about $0.5 d$, the rotation frequency of $1.5 \mathrm{~Hz}$ or $S t=0.41$ and the convective velocity of $0.7 \mathrm{U}$, and the horseshoe vortex before the first central pile had the diameter of $0.3 d$, the rotation frequency of $0.9 \mathrm{~Hz}$ or $S t=0.25$ and the convective velocity of $0.56 U$.

\section{REFERENCES}

Akilli, H. \& Rockwell, D. 2002. Vortex formation from a cylinder in shallow water. Phys. Fluids. 14(9): 2957-2967.

Ataie-Ashtiani, B. \& Aslani-Kordkandi, A. 2012. Flow field around side-by-side piers with and without a scour hole. European J. Mechanics - B/Fluids 36(6): 152-166.

Chen, G., Du X.D. \& Wei Q.D. 2000. The effects of cylinder shape on the primary horseshoe vortex of juncture flow. $9^{\text {th }}$ Symposium on Flow Visualization. 54: 1-9.

Dargahi, B. 1990. Controlling mechanism of local scouring. $J$. Hydr. Eng. 116(10): 1197-1214.

Ettema, R., Kirkil, G. \& Muste M. 2006. Similitude of largescale turbulence in experiments on local scour at cylinders. J. Hydr. Eng. 132(1): 33-40.

Kirkil, G. \& Constantinescu, G. 2015. Effects of cylinder Reynolds number on the turbulent horseshoe vortex system and near wake of a surface-mounted circular cylinder. Phys. Fluids 27: 075102-1-25.
Melville, B.W. 1997. Pier and abutment scour: Integrated approach. J. Hydraulic Eng. 123(2): 125-136.

Roulund, A., Sumer, B.M., Fredsoe, J. \& Michelsen, J. 2005. Numerical and experimental investigation of flow and scour around a circular pile. J. Fluid Mech. 534: 351-401.

Sumer, B.M., Bundgaard, K. \& Fredsoe, J. 2005. Global and local scour at pile groups. Int. J. Offshoe and Polar Eng. 15(3): 204-209.

Vinogradnyi, G.P., Voskoboinick, V.A., Grinchenko, V.T. \& Makarenkov, A.P. 1989. Spectral and correlation characteristics of the turbulent boundary layer on an extended flexible cylinder. J. Fluid Dyn. 24(5): 695-700.

Voskoboinick, A.A., Voskoboinick, A.V. \& Voskoboinick, V.A. 2008. Visualization of the junction flow around of group bridge pier. Bulletin of Donetsk University, Series A: Natural Sciences. 1: 219-227.

Voskoboinick, A.A., Voskoboinick, A.V., Voskoboinick, V.A. $\&$ Nikishov, V.I. 2014. Pressure fluctuations on the scour surface. Applied hydromechanics 16(2): 27-35.

Voskoboinick, A.V., Voskoboinick, V.A., Tereschenko, L.M. 2007. Local sediment scours before group of bridge piers. Bulletin of Donetsk University, Series A: Natural Sciences. 1: 120-126.

Voskoboinick, V., Kornev, N. \& Turnow, J. 2013. Study of near wall coherent flow structures on dimpled surfaces using unsteady pressure measurements. Flow Turbulence Combust. 90(4): 709-722.

Voskoboinick, V.A. 2008. Velocity field statistical characteristics of the junction flow around the three-row pile grillage. Bulletin of Donetsk University, Series A: Natural Sciences 2: 130-137.

Voskoboinick, V.A. 2012. Transformation of a flow energy to the wall-pressure fluctuation field. Acoustic bulletin. 15(1): 3-21.

Voskoboinick, V.A., Grinchenko, V.T. \& Makarenkov A.P. 2003. Correlation characteristics of a wall pressure fluctuation field in a turbulent boundary layer induced by a longitudinal flow along a flexible extended cylinder. Intern. J. Fluid Mech. 30(6): 644-650.

Voskoboinick, V.A., Nikishov, V.I., Voskoboinick, A.A. \& Voskoboinick A.V. 2014. Influence of grouping of the bridge piers on scour. Science-Based Technologies. 22(2): $229-235$ 